\title{
Springing Forward: Changes in Phenology of Native Plant Species in Southern Oregon Prairies as a Result of Experimental Climate Change
}

\author{
Maura Kanner, Environmental Science*; Laura McCullough, Environmental \\ Science $^{* *}$; Kathryn Nock, Environmental Studies ${ }^{* * *}$
}

\begin{abstract}
Changes in land use, agriculture, and the introduction of invasive species have left prairies of the Pacific Northwest at risk of exacerbated disturbance as a result of changes in climate. A shift in phenology-the timing of biological events (e.g., flowering)-is one of the projected consequences of climate change for many plant species, which may lead to disruptions in community structure such as mismatches in timing of plant-herbivore and plant-pollinator interactions. Shifts and disruptions among prairie species in the Pacific Northwest as a result of climate change are generally unknown. Thus, we examined timing of flowering and seed set under three experimental climate treatments in Selma, Oregon. Treatments included: a control, a $2.5^{\circ} \mathrm{C}$ increase in temperature, and a 40\% reduction in rainfall to mimic extreme drought. From 20 March to 27 May 2016, we visited the climate plots weekly and recorded the abundance of flowering plants and the number of flowers each plant produced for 15 native grass and forb species. Only three produced sufficient flowers to analyze. Sidalcea malviflora ssp virgata, an endemic perennial forb species, flowered earlier but produced fewer plants and flowers per plant in the heated treatments. Navarretia pubescens and Clarkia purpurea, two annual forb species, trended towards flowering earliest in the heated plots, but this was not statistically significant. Continued data collection over the next several years will enable parameterization of a model to predict these plants' responses to projected climate change, including their predicted future distributions and their annual growth timeline.
\end{abstract}

\footnotetext{
* Maura graduated from the University of Oregon in the spring of 2016 and studied Environmental Science with an emphasis in Physical Science and a minor in Geology. She spent the winter and spring of her senior year as well as the summer after graduation conducting the research used in this study. Currently she is working as a Geologist in the Bay Area and hopes to pursue a higher education in Planetary Science. Please direct correspondence to maurakanner@gmail.com.

** Laura graduated from the University of Oregon in the fall of 2016 with a degree in Environmental Science focused on life science and a minor in Biology. In the fall of 2017, Laura will begin work towards a master's degree in Biology at the University of Oregon, studying the biogeochemical interactions between projected climate change and organic soil systems. Please direct correspondence to mcculloughlaura2@gmail.com.

*** Kathryn will be graduating from the University of Oregon in the spring of 2017 with a degree in Environmental Studies focused on social sciences and humanities, as well as a minor in Biology, with an emphasis in Botany. She plans to continue her education by examining the cultural roots of climate change, and how to improve communication between scientists and the general public. Please direct correspondence to kathryn.m.nock@gmail.com.
} 


\section{INTRODUCTION}

In a region of the country known best for its old-growth forests, snow-capped mountains, and raging rivers, it may seem unexpected for an assortment of often ignored upland prairies to be a primary source of insight regarding the impacts of our changing climate on the native grass and forb species in the Pacific Northwest. Prairies are common between the Coast and Cascade Ranges, and their vulnerability to climate change makes them a favorable place to conduct climate manipulation experiments to examine the implications of predicted changes in temperature and precipitation on the native plants that reside there (Sala et al. 2000). During the twentieth century, the average temperature in the Pacific Northwest increased $0.7^{\circ}-0.9^{\circ} \mathrm{C}$ (Mote 2003). The regional climate predictions for the Mediterranean climate zone of the Pacific Northwest show that there are likely to be increasingly warmer temperatures year-round and less precipitation in the already dry summer months (Mote and Salathe 2010). This directly influences plant phenology because temperature and precipitation are the two main drivers behind a plant's life cycle (Walther 2002).

Plant phenology-the timing of different stages of the plant life cycle including germination, flowering, fruiting, and senescence-is one of the most tangible ways to track and record the impacts of temperature and precipitation change (Walther 2002). In Mediterranean zones, precipitation levels impact plants at the beginning of their life cycle while temperature acts as a limitation for growth (Gordo and Sanz 2010). As the plants progress through their life cycle so does the season around them and by the time the plants begin to mature, the dry season arrives, allowing for temperature and sunlight to increase and for maximum photosynthesis to occur (Gordo and Sanz 2010). During the dry season, precipitation replaces temperature as the limiting growth factor (Gordo and Sanz 2010). As primary producers for most ecosystems, any changes made to the timing of the plant life cycle is likely to have cascading impacts through all trophic levels placing increased pressures on interspecies relations (Parmesan 2006, Memmott et al. 2015, Gezon 2016).

Plant-pollinator interactions have the potential to become mismatched as a result of an independent alteration of a plant's phenological cycle (Forrest 2015). These asynchronicities can be found in circumstances when the flowering season of a specific plant fails to align with the active season of the pollinators that it has co-evolved with, potentially decreasing the population of one or both species (Memmott et al. 2015). In one hypothetical model, a threat of a loss in food supply of $17-50 \%$ has been predicted for pollinators due to half of their historically observed period of activity occurring when there are no longer any flowers present (Memmott et al. 2015). However, these responses are extremely situational, each depending on specific interactions between species and locations. In a recent study on Claytonia lancelota, a perennial herb, Gezon (2016) showed that the risk of plant phenology shifting forward has little effect on pollinator interactions, but increases the plant's vulnerability to freezing. 
Why study prairies of the Pacific Northwest, given that climate change is happening all around the world? Mediterranean grasslands often host desirable conditions for biodiversity and endemism due to their rich soil nutrient levels as well as their flat geography (Salinas et al. 2000). However, these same characteristics make upland prairies an ideal place for large-scale agricultural production and urban industrialization, often leading to habitat fragmentation and improper burning regimes. In the Pacific Northwest specifically, $99 \%$ of the prairies that have existed historically in the region are now gone primarily as a result of changes in land use (Noss et al. 1995).

Constant human disturbance in the region exacerbates the threats associated with changes to weather patterns, putting Mediterranean prairies (such as the ones included in this project) at some of the highest risk of being impacted by climate change (Sala et al. 2000). In fact, climate change is predicted to surpass land disturbance in terms of risks to biodiversity loss within the next century (Pereira et al. 2010). Considering the notable amount of human-induced disturbance upland prairies have experienced, these Mediterranean ecosystems are an important resource for specific case studies regarding the impacts of climate change upon their inhabitants.

To further understand these consequences on a local level, we worked alongside members of the HOPS ("Heating of Prairie Systems") project funded by the National Science Foundation MacroSystems Biology Program. The HOPS project is a long-term study examining the impacts of climate change on the demography, phenology and overall fitness of fifteen species of grasses and forbs native to prairies in the Pacific Northwest. Plant responses are being measured at three experimental sites, each highlighting a different level of temperature and drought severity from central Washington down to southern Oregon. At each site three "climate treatments" are implemented, including: reduced rainfall ("drought"), increased temperature ("heated"), and a control (PfeiferMeister et al. 2013). There were three objectives for our study: to understand the effect of differing "climate treatments" relative to a control on A) the timing of flowering, B) the overall green biomass using Normalized Difference Vegetative Index (NDVI), and C) the number of flowers as a proxy for reproductive fitness of each species. Specifically, we hypothesized the following:

H1) Due to an increase in temperature, native plants in heated plots will flower earlier than those in the drought or control plots.

H2) Due to a decrease in soil moisture, native plants in drought and heated plots will develop seed and senesce earlier than control plots.

H3) Green biomass (NDVI) will peak and senesce earlier for heated plots due to the increase in temperature.

H4) Green biomass will have an abbreviated growing season in the drought treatment due to a decrease in soil moisture. 
Despite the vulnerability of prairie habitats, there has been surprisingly little research done on the subject within the Pacific Northwest, and specifically in southern Oregon. While there have been assorted studies occurring on agricultural lands, and Midwestern prairies with mostly $\mathrm{C}_{4}$ grasses, there is little data regarding coastal Mediterranean prairies (e.g., Zavaleta et al 2003). This is problematic because Mediterranean $\mathrm{C}_{3}$ prairies (like those present in southern Oregon) are predicted to respond differently and be drier than habitats that have been studied more frequently in the past (Pfeifer-Meister et al 2015). In contrast to the relatively consistent climate patterns of continental grasslands, those in the Mediterranean zone are more likely to experience larger variation between seasons, which may be exacerbated by climate change (Stromberg et al 2007). Variation of (and dependence on) the timing in which the dry and wet seasons occur supports the importance of using phenology as a catalyst for understanding the impact of climate change on native plants. Our main goal is to add to the bank of inquiry regarding these vital interactions and systems.

\section{METHODS}

Our site was located in Selma, Oregon, 20 miles west of Grants Pass, at the Siskiyou Field Institute (SFI). The Klamath-Siskiyou region contains over 3,500 taxa of vascular plants, including 281 endemic taxa, making it "an Area of Global Botanical Significance" according to the World Conservation Union (Smith and Sawyer 1988, Marsden 2001). Due to its unique botanically and geologic diversity, the World Wildlife Fund (WWF) chose this region to be one of their five conservation priorities as human activity continues to threaten its ecological richness (Marsden 2001).

Our three experimental climate treatments included control $(n=5)$, heating $(n=10)$, and drought treatments $(\mathrm{n}=5)$. The heat treatment increased the plot temperature by $2.5^{\circ} \mathrm{C}$ above ambient using infrared heaters (Pfeifer-Meister et al 2013). The drought treatment decreased precipitation by 40\%-a percentage calculated by Paul Reed using the "Precipitation Trends Tool" and the "Precipitation Manipulation Tool," found on Drought-Net's website, and referencing "The International Drought Experiment: a distributed approach to assess terrestrial ecosystem responses to extreme drought" also by Drought-Net (2015). Drought treatments were constructed using transparent, vshaped acrylic bands that lack a UV filter and are supported by a wooden frame at a $20^{\circ}$ so that rainwater can drain from them (Yahdjian and Sala 2002). The treatments were initiated in late February 2016. In the fall of 2014, the fifteen total focal species were broadcast into each plot to encourage establishment. In December 2015, the plots were reseeded with 200 seeds per species in eight random locations within each plot.

Data were collected for all species once a week at the Siskiyou Field Institute in Selma, Oregon between 20 March 2016 and 27 May 2016. Of the fifteen focal species used in this study, only three species flowered in sufficient quantities within this timeframe to be used as part of the analysis for this study (Clarkia purpurea, Sidalcea malviflora ssp. virgata, and Navarretia pubescens). The number of buds, number of flowers, number of 
seeds/fruit on each plant, along with the total number of plants was recorded for each plot. Moreover, we recorded whether a species was present in a plot but not yet flowering, as well as if a species was not present at all. Forbs species were analyzed for evidence of bud, flower, and/or fruit development. Grass species with more than six tillers were analyzed for evidence of seed development. Remote sensing imagery was used to measure NDVI, which is an analysis that determines how much living green vegetation fills the space in a given image. Five images per plot were taken weekly, starting on the northwestfacing side of the plot and moving counterclockwise and ending on the northeast side. Data were analyzed for reproductive timeline, NDVI, number of flowering plants per plot, and flowers per plant using one way analysis of variance (ANOVA) in the program SPSS (Kanner et al 2016). The alpha level used to indicate significance in our analysis was 0.1.

\section{RESULTS}

\subsection{PHENOLOGY}

Flowering tended to occur earlier in the heated plots for all species, although this was not statistically significant ( $\mathrm{p}>0.450$, Figure 1). Sidalcea malviflora flowered at least two weeks earlier in heated plots, but produced seed at the same time for all three treatments. Neither C. purpurea nor N. pubescens produced seed during data collection. NDVI, as a measure of green biomass, quickly began to diverge among treatments after initiation in late Feb (Figure 2). NDVI peaked and senescence began earliest in the heated plots when compared to the control plots, but only the earlier senescence was significant $(p=0.056$, Figure 2). NDVI in drought plots was intermediate between control and heated plots.

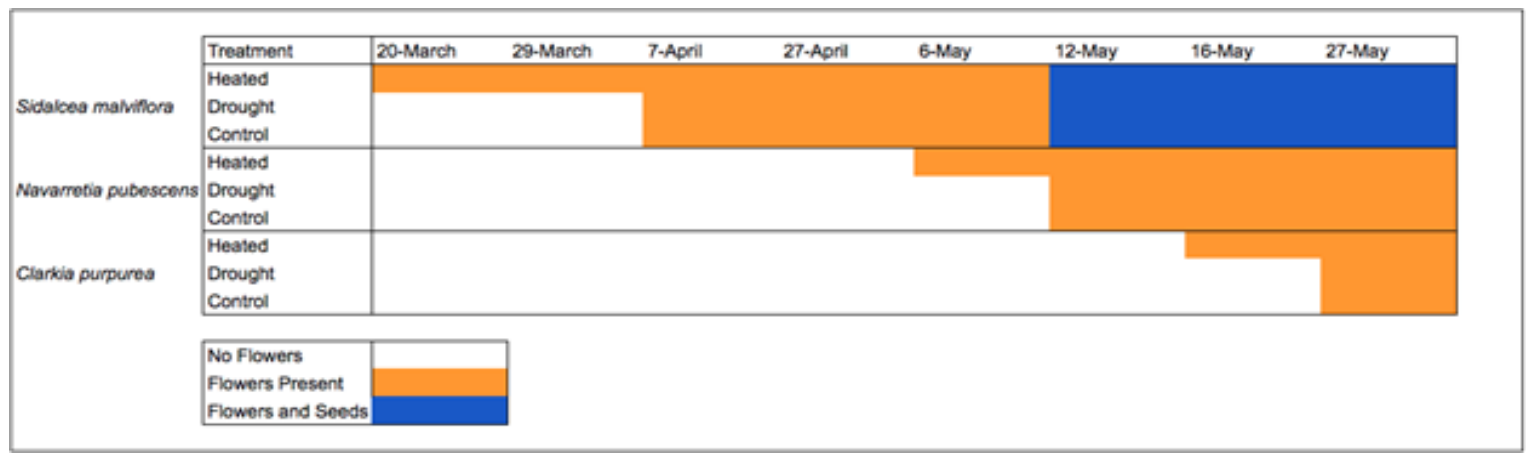

Figure 1: Reproductive timeline of first flowering and seed set in heated, drought, and control plots for Sidalcea malviflora, Navarretia pubescens, and Clarkia purpurea for dates March 20, 2016 through May 27, 2016. 


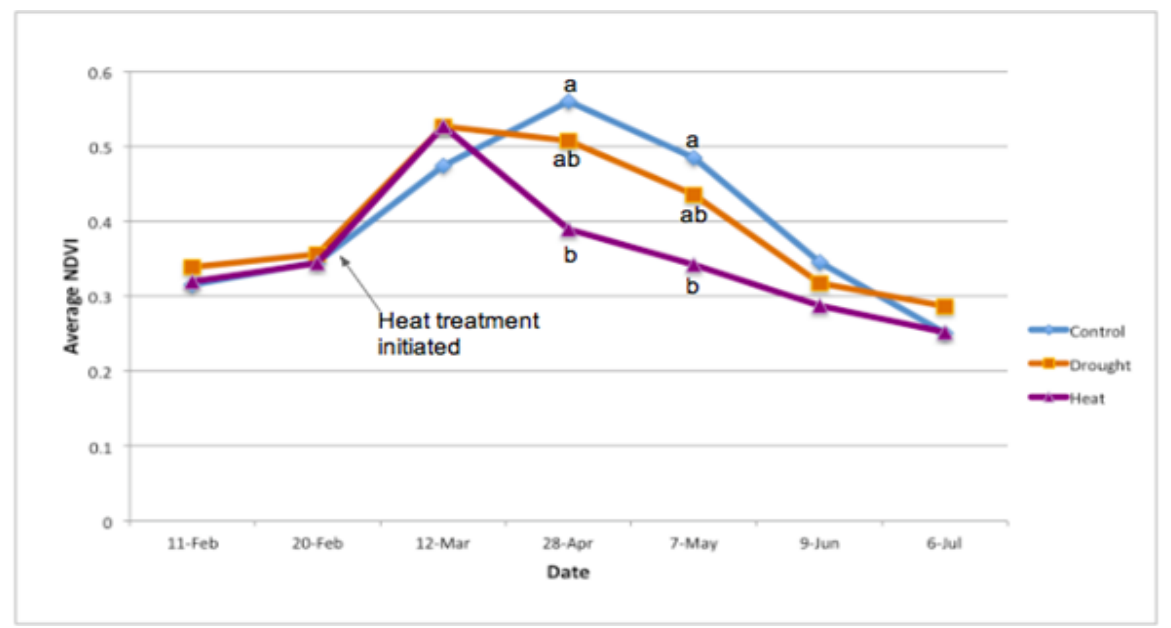

Figure 2: NDVI measurements between February 11, 2016 and July 6, 2016 for control, drought, and heated plots. Differences between plots were marginally significant on April 28 $(\mathrm{p}=0.092)$, and May $7(\mathrm{p}=0.056)$. Different letters indicate significant differences among treatments within a sampling date.

\subsection{FITNESS}

Sidalcea malviflora produced fewer flowers per plant $(\mathrm{p}=0.003$, Figure 3$)$ and fewer flowering plants $(\mathrm{p}<0.040$, Figure 4$)$ in the heated treatment. No differences were detected between the drought and control treatment for flowers per plant or number of flowering plants. For C. purpurea and N. pubescens, we found no differences in flower number or number of flowering plants during the period of observation.

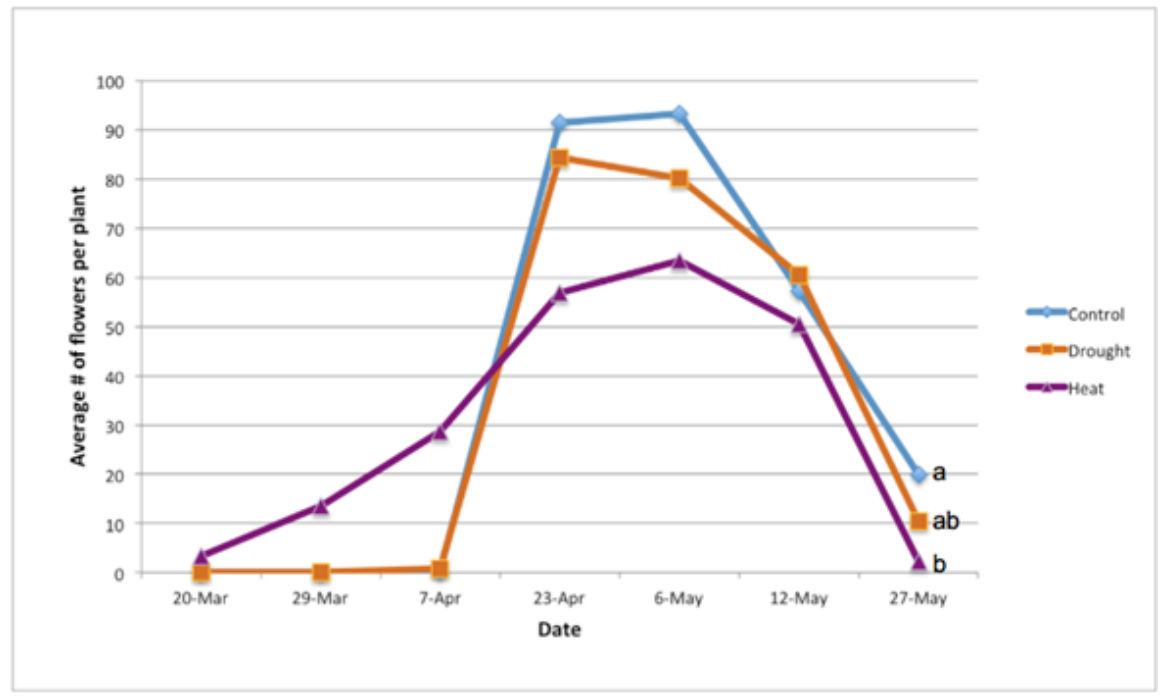

Figure 3: Number of flowers per plant for Sidalcea malviflora in control, drought, and heated plots between March 20, 2016 and May 27, 2016. Differences between treatments were significant on May 27, 2016 ( $\mathrm{p}=0.003$ ). Different letters indicate significant differences among treatments within a sampling date. 


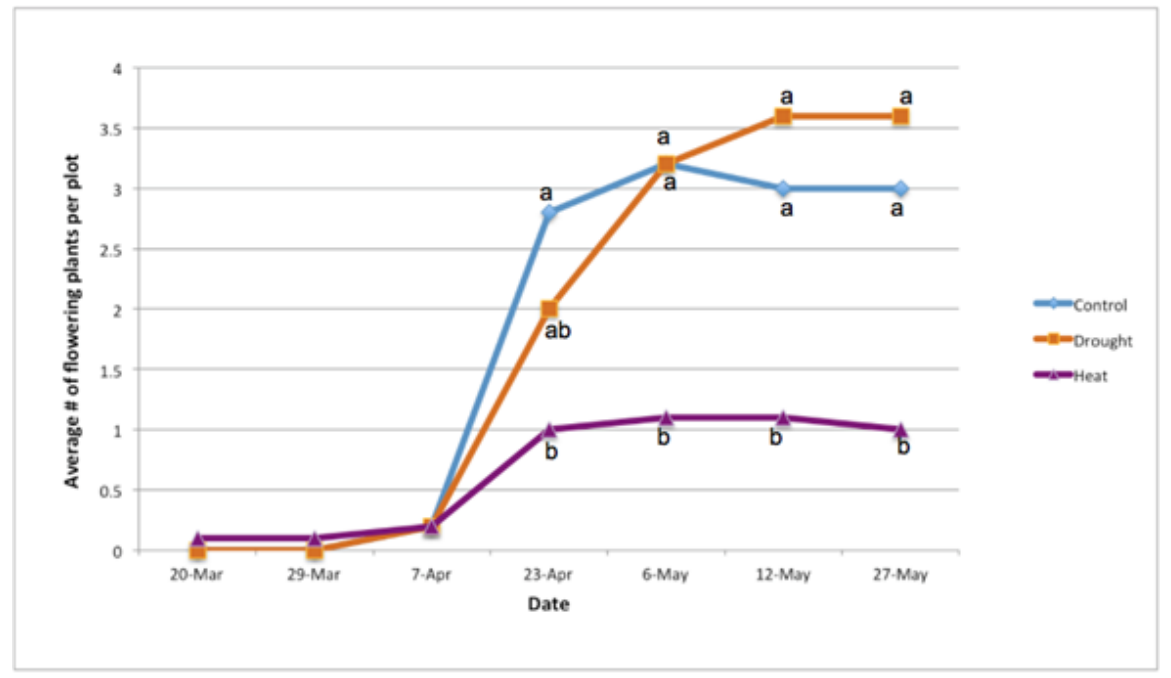

Figure 4: Number of flowering plants per plot for Sidalcea malviflora in control, drought, and heated plots. The differences between treatments were marginally significant for April 23, 2016 ( $\mathrm{p}=0.090)$, and significant for May 6, $2016(\mathrm{p}=0.037)$, May 12, $2016(\mathrm{p}=0.019)$, and May 27, 2016 $(\mathrm{p}=0.008)$. Different letters indicate significant differences among treatments within a sampling date.

\section{DISCUSSION}

Our observations and analysis in Southern Oregon imply that projected climate change will have a negative phenological effect on select native plants. Those that are able to successfully grow and flower may have fewer-than-average reproductive structures, further reducing their reproductive fitness. We observed that few of the fifteen species included in the whole project performed well in southern Oregon, our site with the most extreme Mediterranean climate, especially in comparison to the two sites farther north along the gradient. The fact that heated plots peaked and senesced first with the lowest average green biomass could mean that under predicted climate change there will be less productivity (Fig. 2). This reduction in productivity of native Southern Oregon plants could result in a decline in success and productivity of other vital forms of life, specifically pollinators local to the region.

Since it has been documented that spring phenology events at temperate latitudes have experienced an advancement of 2.5 days per decade since 1971 as well as a temperature increase well above $0.5^{\circ} \mathrm{C}$ (Körner and Basler 2010), it is no surprise that flowering occurred at least one week sooner in the heated plots (Fig. 1). The predicted change in temperature over the next 50 years is likely to have a detrimental effect on the success of these native plants, as our results show that the heated plots had fewer flowering plants and flowers per plant than the drought and control treatments for S. malviflora (Fig. 3, 4). In other words, higher temperatures may result in a decrease in plant numbers and reproductive structures, suggesting the species' success could be compromised under predicted climate change. 
Our work shows that heating (or warming) can affect the timing of flowering, but the timing of fruit development and senescence remained inconclusive due to the length of our study. Sidalcea malviflora was the only species observed during the timeframe of this study to go to fruit. According to a study on wildflower phenology done by CaraDonna et al (2014), a shift in the timing of first flowering events does not necessarily have a significant impact on whether, or how, peak and last flowering events will shift. Although heated treatments flowered first for S. malviflora, all three treatments went to fruit at the same time, suggesting that the heat treatment (or warming) affects time of flowering but not the time of fruiting (Fig. 1) (CaraDonna et al. 2014). This kind of data is vital to our understanding of how climate change will impact the full phenological cycle of these plants. A shift in phenology may impact interspecies relationships with consequences like opening up previously filled niches to invasive species, or mismatching the life cycles of plants with their pollinators.

Several sources of error occurred throughout this study. The week of April 23rd, data was taken by a team of undergraduates participating in the University of Oregon's Environmental Leadership Program and on the week of May 16th data was taken by two graduate students associated with the Bridgham Lab. The data from these two weeks slightly differ from the data recorded by us in terms of what specifically was being counted and number of plants per plot, thus generating error in the results. Lastly, although data was taken roughly once a week, the days that data were recorded were not evenly spaced out; the range of days between data recordings is four to sixteen days. In future studies it will be important to extend the study period to begin earlier and end later in order to collect sufficient phenological data for all species included.

\section{CONCLUSION}

This study, and those similar to it, will be beneficial in future discussions regarding the development, restoration, and protection of native prairies. Although our results are not entirely conclusive, they nonetheless increased our understanding of how Mediterranean ecosystems respond to changes in the climate. While many things can be inferred from this study, two specific concepts stood out to us. First, that the phenologies of native PNW plant species are likely to shift due to the fact that flower timing and senescence heavily relies on temperature-thus warmer temperatures will induce earlier flowering as well as senescence. Second, it is inferred that a warming climate will increase the adaptive pressures on native plant populations to move north of their current native geographic range, increasing the potential of displacing pre-existing populations in these regions.

During our research, we came to a realization of one vital component within this study that should be given more attention: the difference in fitness and resilience under climate change-like conditions of perennial and annual plant species in native prairies in the Pacific Northwest. In previous research done by Pfeifer-Meister et al (2015), it was posited that perennial plants (i.e., Sidalcea malviflora) would be able to withstand projected climate change more so than annual plants (i.e., Navarretia pubescens and Clarkia 
purpurea). This is due to the role germination plays in plant survival; the survival of a plant is not dependent on how well it germinates, if at all. More specifically, if a perennial plant misses its window to germinate one year, it has a chance to adapt and germinate the next year whereas an annual plant would not have that opportunity-leading to the potential endangerment or extinction of its species. However, a different study suggests that higher temperatures will fall in favor of annual species rather than perennial species due to an extended growing period that would widen the window annuals have to germinate and grow (Dijkstra et al 2010). As this experiment continues over the next several years, we would recommend incorporating this variable to better understand the extent that these plant species will be affected by climate change. It would be beneficial to study and understand the growing patterns more deeply of these two categories of species (e.g., does temperature influence one more than the other?) since both already differ in growing patterns and are likely to shift in conjunction with projected climatechange.

Plants are sessile, but their seeds and pollen can disperse to new geographic areas where the climate may be more conducive to growth and reproduction. Species growing in heated plots in an area north of their native range essentially grew just as one would expect them to grow in an ideal world where their native home is not warming up (PfeiferMeister et al 2015). This shows that, if these species can disperse to more conducive climates, there is a strong likelihood of a poleward shift of these plants and ecosystems in the future. This could potentially lead to drastically altered community composition within ecosystems. The success of perennials vs. annuals previously discussed would also be a key component in this observation; different phenologies and growing patterns would have the possibility of controlling the success of a plant's ability to shift its range. Moreover, shifting phenologies of native plants could imply shifting phenologies of invasive plants. With the occurrence of differing shifts in phenologies, the ability for invasive species to fill open niches that once belonged to native plants could increase, thus further altering the prairie plant community (Hellman et al 2008). While many native species have evolved to specific climates, invasive species tend to tolerate a much wider climate range that allows them to survive and spread in the ecosystems when native plants may no longer be able to (Hellmann et al 2008).

But what can we do? Climate change is much bigger than the 20 experimental plots sitting in Selma, Oregon; how can these changes be mitigated on a regional level? We can study these plants' reactions to projected climate change for years, even decades, and continue to unravel what may be a dismal future for PNW prairies, but what these ecosystems are in critical need of is action. For example, creating wider buffers around prairies from human activity, controlled burning to abate invasive species, reducing conifer encroachment, and restoring plant communities by manually planting and spreading seeds can all have beneficial effects on endangered upland prairies. Perhaps the strongest form of action, however, is education. In contrast to the charismatic landscapes of the Pacific Northwest's forests, mountains, and rivers, grasslands are often deemed as 
"empty space." However, the shifts in phenology and biodiversity that have already been seen within upland prairie communities can be used as a lesson of ecosystem equality, the fragility of interconnectivity, and as a reminder that it is not too late to implement change (Parmesan 2006; Memmott et al. 2015; Gezon 2016). By informing regional and global communities about the threats Mediterranean systems are faced with, principles can be morphed, ideas can be created and further actions undertaken. This is just one of a multitude of ecosystems hanging by a thread as climate change unfolds-just one domino in an upright formation of many. It is a race against time, and the success of species could be reliant on our understanding of their ability to adapt and shift location in order to spring forward and predict the potential consequences of climate change.

\section{ACKNOWLEDGEMENTS}

We would like to thank Laurel Pfeifer-Meister for mentoring, encouraging, and helping guide our research and scientific endeavors; Scott Bridgham for supporting us and granting us access to the resources provided by the Bridgham Lab; and Bitty Roy, Bart Johnson, Matt Krna, Paul Reed, Lauren Hendricks and Graham Bailes for acquiring data and assisting us in the field. We would also like to thank the SPUR Program and the National Science Foundation's MacroSystem Biology Program for generously funding this study (\#EF-1340847). Lastly, a big thanks to the Siskiyou Field Institute for allowing us to conduct research on their property.

\section{REFERENCES}

CaraDonna, P. J., Ilera, A. M., \& Inouye, D. W. (2014). Shifts in flowering phenology reshape a subalpine plant community. Proceedings of the National Academy of Sciences of the United States, 111(13), 4916-4921.

Dijkstra, J. A., Westerman, E. L., \& Harris, L. G. (2011). The effects of climate change on species composition, succession and phenology: A case study [PDF]. Global Change Biology, 17(7), 2360-2369.

Drought-Net. (2015). The International Drought Experiment: a distributed approach to assess terrestrial ecosystem responses to extreme drought [PDF]. Retrieved February 28, 2016, from http://www.drought-net.org/

Gezon, Z. J., Inouye, D. W., \& Irwin, R. E. (2016). Phenological change in a spring ephemeral: Implications for pollination and plant reproduction [PDF]. Global Change Biology, 22(5), 1779-1793.

Gordo, O. \& Sanz, J. J. (2010). Impact of climate change on plant phenology in Mediterranean ecosystems. Global Change Biology. 16, 1082-1106. 
Hellmann, J. J., Byers, J., Bierwagen, B. G., \& Dukes, J. S. (2008). Five potential consequences of climate change for invasive species [PDF]. Conservation Biology, 22(3), 534-543.

Kanner, M., McCullough, L., \& Nock, K. (2016). Springing Forward: phenology data. University of Oregon. Unpublished raw data.

Körner, C., \& Basler, D. (2010). Phenology under global warming [PDF]. Plant Science, 327(5972), 1461-1462.

Marsden, J. K., \& Jules, E. S. (2001). The Siskiyou Field Institute: Supporting Science Education and Research in the Siskiyou Mountains and the Greater Klamath Region [PDF]. Kalmiopsis, 7, 17.

Memmott, J., Craze, P. G., Waser, N. M., \& Price, M. V. (2007). Global warming and the disruption of plant-pollinator interactions [PDF]. Ecology Letters, 1O(8), 710-717.

Mote, P. W. (2003). Trends in temperature and precipitation in the Pacific Northwest. Northwest Science, 77(4), 271-282.

Mote, P. W. and E. P. Salathé. (2010). Future climate in the Pacific Northwest. Climatic Change, 102(1-2), 29-50.

Noss R. F., LaRoe E. T. III, \& Scott J. M. (1995). Endangered Ecosystems of the United States: A Preliminary Assessment of Loss and Degradation. National Biological Service, Washington, DC, USA.

Parmesan, C. (2006). Ecological and evolutionary responses to recent climate change [PDF]. Annual Reviews in Ecology Evolution and Systematics, 37, 637-669.

Pereira H. M., Leadley P. W., Proença V et al. (2010). Scenarios for global biodiversity in the 21st Century. Science, 33o(6010), 1496-1501.

Pfeifer-Meister, L., Bridgham, S. D., Little, C. J., Reynolds, L. L., Goklany, M. E., \& Johnson, B. R. (2013). Pushing the limit: Experimental evidence of climate effects on plant range distributions [PDF]. Ecological Society of America, 94(10), 2131-2137.

Pfeifer-Meister, L., Bridgham, S. D., Reynolds, L. L., Goklany, M. E., Wilson, H. E., Little, C. J., ... \& Johnson, B. R. (2015). Climate change alters plant biodiversity in mediterranean prairies along the west coast, usa [PDF]. Global Change Biology, 22(2), 845-855.

Sala, O. E., Chapin, S. F., Armesto, J. J., Berlow, E., Bloomfield, J., Dirzo, R., ... \& Wall, D.H. (2010) Global Biodiversity Scenarios for the Year 2100. Science, 287(5459) 17701774 . 
Salinas, M. J., Blanca, G. \& Romero, A.T. (2000) Riparian vegetation and water chemistry in a basin under semiarid Mediterranean climate, Andarax River, Spain. Environmental Management, 26(5), 539-552.

Smith Jr, J. P., \& Sawyer Jr, J. O. (1988). Endemic vascular plants of northwestern California and southwestern Oregon. Madroño, 35(1), 54-69.

Walther, G., Post, E., Convey, P., Menzel, A., Parmesan, C., Beebee, T. J., ... \& Bairlein, F. (2002). Ecological responses to recent climate change. Nature, 416(6879), 389.

Windauer, L. B., Slafer, G. A., \& Ravetta, D. A. (2004). Phenological responses to temperature of an annual plant and a perennial lesquerella species [PDF]. Annals of Botany, 94(1), 139-144.

Yahdjian, L., \& Sala, O. E. (2002). A rainout shelter design for intercepting different amounts of rainfall [PDF]. Oecologia.

Zavaleta, E. S., Shaw, R. M., Chiariell, N. R., Mooney, H. D., \& Field, C. B. (2003). Additive effects of simulated climate changes, elevated $\mathrm{CO} 2$, and nitrogen deposition on grassland diversity. PNAS, 1OO(13), 7650-7654. 